\title{
Optimal Insider Strategy with Law Penalties $^{*}$
}

\author{
José Fajardo ${ }^{\dagger}$
}

\author{
Contents: 1. Introduction; 2. Model; 3. Optimization Problem; 4. Example; 5. Simulations; 6. Optimal \\ Penalties; 7. Conclusions; Appendix. Proof of the Main Theorem. \\ Keywords: Insider Trading, Law Penalties, Social Welfare. \\ JEL Code: G11, K42.
}

We study the optimal continuous trading strategy of an insider who is subject to the possibility of law penalties due to her illegal trading activity. Also, we discuss how to obtain the optimal penalty rule in order to maximize a welfare function.

Estudamos a estratégia contínua ótima de um insider que esta sujeito as penalidades da lei devidas a suas acividades de negócios ilegais. Também, analizamos como obter a regra de penalidade ótima que maximize uma funçao de bem-estar.

\section{INTRODUCTION}

It is very well known and documented that in many markets some traders had more information than others, more exactly they construct their strategies based on the knowledge of future events, this future information is known as the inside information and these traders are known as being the insiders of the market. Of course this kind of trading is illegal and the insiders are exposed to the risk of being penalized by the law.

The evidence of insider trade and possible implications have been analyzed in previous literature for some markets, as for example in the credit default swap and future markets, by Acharya \& Johnson (2007) and Hsu \& Lee (2014), respectively. Also, the optimal strategy of the insider had been analyzed in many contexts, see for example Pikovsky \& Karatzas (1996), Elliott \& Jeanblanc (1999), Grorud \& Pontier (1998), Corcuera, Imkeller, Kohatsu-Higa, \& Nualart (2004), Kohatsu-Higa \& Sulem (2006) and Di Nunno, Meyer-Brandis, Øksendal, \& Proske (2006), among others. But, in all of them the risk to be penalized by the existence of insider trading law is not taken into account. One way to avoid the possibility to be penalized is to use inconspicuous strategies, as in the equilibrium models of Kyle (1985) and Back (1992), see also Campi \& Çetin (2007) and Ly Vath (2007). It requires aggregate demand to be a Brownian motion. $^{1}$

\footnotetext{
"I would like to thank the comments of an anonymous referee that helps to improve the present version of the paper. Also, I would like to thank CNPq from Brazil for financial support. The usual disclaimer applies.

${ }^{\dagger}$ Escola Brasileira de Administração Pública e de Empresas - FGV/EBAPE. Praia de Botafogo, 190, 4º e 5ªndares, Rio de Janeiro. CEP 22250-900. E-mail: pepefb@gmail.com

${ }^{1}$ It means that when adding the insider's portfolio to the rest of portfolios in the market it remains a noise, that is, the regulator can not observe any abnormal behavior. This kind of strategy is called inconspicuous.
} 
On the other hand, in the default literature the possibility to dishonor commitment is considered but the traders incurs in penalties proportional to the size of the dishonored part, see for example Dubey, Geanakoplos, \& Shubik (2005) and Fajardo (2009). We can understand this penalties as a disutility caused by its illegal behavior, as for example loss of credit or being in jail. In the insider trading context, we can also think on penalties due to the use of insider information, in this way we can size the crime by the gains produced by the insider trading or the loss avoided. In the latter model we can observe directly the proportional penalties in the market, while in the former not.

More exactly, in the US law the penalties, both civil and criminal, for insider trading are severe. First, there are private civil remedies, as found in Section 20A of the Exchange Act of 1934. Persons who are harmed by insider trading can bring actions in most circumstances to recover the illegal profits (or avoided losses) enjoyed by wrongful traders in contemporaneous trading. Furthermore, the US Securities and Exchange Commission (SEC) has the authority to impose criminal penalties, civil penalties, and punitive civil awards against wrongful traders. Congress passed the Insider Trading Sanctions Act in 1984 to toughen penalties for illegal traders. The civil penalty in such a suit can include disgorgement of profits and a penalty of up to three times the ill-gotten profits.

In this paper we combine the utility penalty approach and the stochastic optimization approach, used in the above literature, to capture a more realistic insider trading behavior. Basically, given a specific kind of insider's information $\operatorname{set}^{2}$ we solve the optimization problem for a logarithmic utility investor who in face linear utility penalties due to the possibility to incur in law penalties and then compute the additional utility obtained by the insider. More precisely, the optimal solution obtained for the insider will be a function of the probability of being captured by the market regulator and the proportional constant used in the linear penalty function, that can be interpreted as the severity of the law. Obtaining in this way an economically and meaningful strategy for the insider. Of course, in practice more severe penalties can occur, as for example the loss of the license to trade. Finally, we study the penalty rule that maximize a kind of welfare function, finding that full enforcement is the optimal penalty rule.

It is worth noting that DeMarzo, Fishman, \& Hagerty (1998), analyzed the optimal enforcement strategy that maximize welfare in a model were the insider also in face penalties due to her illegal behavior but in a very different discrete-time model. Their results implies that regulators must try to minimize the bid-ask spreads observed in the market. In another related result Liu \& Zhang (2011) study the impact of public information on trading behavior, finding that the existence of such public information makes the market more efficient.

The paper is organized as follows: In section 2 we introduce our model. In section 3 we obtain the optimal strategy. In section 4 and section 5 we have an example and some simulations, respectively. In section 6 we discuss the optimal penalty rule and section 7 concludes.

\section{MODEL}

Let $(\Omega, \mathcal{F}, \mathbf{P})$ be a probability space with filtration $\mathbb{F}=\left(\mathcal{F}_{t}\right)_{[0, T]}$ satisfying the usual conditions, i.e. the filtration is right-continuous and each $\mathcal{F}_{t}$ contains all $(\mathcal{F}, \mathbb{P})$-null sets. Let $T \in(0, \infty)$ be a fixed time horizon and for simplicity we assume that $\mathcal{F}_{0}$ is trivial up to $\mathrm{P}$-null sets.

Let $G$ be a $\mathcal{F}$-measurable random variable with values in a Polish space $(\mathcal{U}){ }^{3}$. Then we call the filtration $\mathbb{G}$ defined by $\mathcal{G}_{t}=\mathcal{F}_{t} \vee \sigma(G), t \in[0, T]$, the initially enlarged filtration of $\mathbb{F}$ and it will describe the insider's information flow. ${ }^{4}$

\footnotetext{
${ }^{2}$ In our model the insider's information set is a set of information that contains all public information and other additional information, to be specified later.

${ }^{3} \mathrm{~A}$ Polish space is a separable completely metrizable topological space.

${ }^{4}$ We recommend the reader the excellent text about enlargement of filtrations: https://www.minet.uni-jena.de/Marie -Curie-ITN/EoF/talks/jeanblanc_introduction.pdf
} 
In our market there will be two agents trading in a continuous-time setting : The ordinary or honest trader who makes his decisions based on all the $\mathcal{F}_{t}$-measurable random variables, the insider or dishonest trader who observe the same information of the ordinary trader plus the additional information given by random variable $G$. We can interpret this additional information as for example $G$ being the price of some asset at time $\tau \geq T$.

The discounted stock price process $S=\left(S_{t}\right)_{t \in[0, \tau]}$ is considered to be a positive continuous $(\mathbf{P}, \mathbb{F})$ semimartingale. To be more exactly we consider a fixed continuous local $(\mathbf{P}, \mathbb{F})$-martingale $M$ with $M_{0}=0$ and a predictable process $\alpha$ such that $\mathrm{E}\left[\int_{0}^{T} \alpha_{t}^{2} d\langle M\rangle_{t}\right]<\infty$, then

$$
d S_{t}=S_{t}\left(d M_{t}+\alpha_{t} d\langle M\rangle\right), \quad \forall t \in[0, T] \text { and } S_{0}>0,
$$

by Itô's formula

$$
S_{t}=S_{0} e^{\int_{0}^{t}\left(\alpha_{s}-\frac{1}{2}\right) d\langle M\rangle_{s}+M_{t}} .
$$

Now by Theorem 2.1 in Jacod (1985) and Lemma 2.8 in Amendinger, Imkeller, \& Schweizer (1998) ${ }^{5}$ we know that $M$ is a $\mathbb{G}$-semimartingale the following process $\widetilde{M}$ is a local $\mathbb{G}$-martingale:

$$
\widetilde{M}_{t}=M_{t}-\int_{0}^{t} \beta_{s}^{G} d\langle M\rangle_{s}, \quad t \in[0, T]
$$

with $\beta=\left(\beta_{t}^{G}\right)$ being a $\mathcal{P}(\mathbb{F}) \otimes \mathcal{U}$-measurable process. Then from the insiders point of view the stock price evolution will be

$$
d S_{t}=S_{t}\left[d \widetilde{M}_{t}+\left(\beta_{t}^{G}+\alpha_{t}\right) d\langle M\rangle_{t}\right]
$$

by Itô's formula

$$
S_{t}=S_{0} e^{\int_{0}^{t}\left(\alpha_{s}+\beta_{s}^{G}-\frac{1}{2}\right) d\langle M\rangle_{s}+\widetilde{M}_{t}} .
$$

We also consider that for the ordinary trader our market is complete in the sense that any bounded random variable $\mathcal{F}_{T}$-measurable can be replicated by a self-financing strategy, that is can be expressed as the sum of a constant and a stochastic integral respect to $S$. Also, for him our market is arbitrage free in the sense that there is a probability measure $\mathbf{Q}^{\text {ord }}$ equivalent to $\mathbf{P}$ on $\left(\Omega, \mathcal{F}_{T}\right)$ such that $S$ is a local $\left(\mathrm{Q}^{\text {ord }}, \mathbb{F}\right)$-martingale.

Now in order to place the insider in complete and arbitrage free market ${ }^{6}$ is sufficient to impose the following assumption.

Assumption 1. The regular conditional distributions of $G$ given $\mathcal{F}_{t}$ are equivalent to the law of $G$, i.e.:

$$
\mathbf{P}\left[G \in \cdot \mid \mathcal{F}_{t}\right](\omega) \sim \mathbf{P}[G \in \cdot], \quad \forall t \in[0, T] \text { and } \mathbf{P} \quad \text { a.s. } \omega \in \Omega .
$$

\section{OPTIMIZATION PROBLEM}

Now in order to set our optimization problem we need to define utility functions, penalty functions and the set of admissible strategies available for the traders.

Definition 1. A function $U:(0, \infty) \rightarrow \mathbb{R}$ is an utility function, if

(i) It is strictly increasing, strictly concave and continuously differentiable on $(0, \infty)$

(ii) Satisfy Inada's condition:

$$
\lim _{x \downarrow 0} U^{\prime}(x)=\infty \text { and } \quad \lim _{x \rightarrow \infty} U^{\prime}(x)=0 .
$$

\footnotetext{
${ }^{5}$ Both results assume that there exist a positive measure $\sigma$-finite $\xi \in(U, \mathcal{U})$ such that $\mathrm{P}\left[G \in \cdot \mid \mathcal{F}_{t}\right] \ll \xi(\cdot)$, for all $t>0, \omega \in \Omega$.

${ }^{6}$ See Amendinger (2000) or Jeanblanc, Yor, \& Chesney (2009).
} 
Examples of utility functions are $U(x)=x^{c}, 0<c<1$, and $U(x)=\log (x)$.

Definition 2. We say that $f:(0, \infty) \rightarrow \mathbb{R}$ is a penalty function if $f$ is a convex function.

Examples of penalty functions are $f(x)=-c x^{\gamma}, 0<\gamma<1$ and $c>0$, that we can interpret as a penalty proportional to the crime and $f(x)=c(x-\bar{G})^{+}$, where $\bar{G}$, can be interpreted as an exogenously fixed maximum average gain level observed in the market and the constant penalty $c$ can be interpreted as the severity of the law. That is, if you have extraordinary gains and insider trade is confirmed, you will have to pay $c$ times the ill-gotten gains, for example three times. As we can see, this kind of linear penalty functions suits very well in our insider model, since we can observe the proportional penalty. Opposite to the default model of Dubey et al. (2005), where the proportional penalties are not directly observed in the market.

Definition 3. Let $x>0$ be the initial wealth and denote by $\mathbb{E}$ a generic filtration.

(i) We say that an $\mathbb{R}$-valued process $\pi=\left(\pi_{t}\right)_{[0, T]}$ is an $\mathbb{E}$-portfolio if it is an $\mathbb{E}$-adapted predictable process and $\int_{0}^{T} \pi_{t}^{2} d\langle M\rangle_{t}<\infty$, P a.s.

(ii) We say that $\mathbb{E}$-portfolio $\pi$ is self-financing if the discounted wealth process denoted by $V(x, \pi)$ satisfies the following equation:

$$
V_{t}(x, \pi)=x+\int_{0}^{t} \pi_{s} d S_{s}, \quad \forall t \in[0, T],
$$

and we denote by $g_{t}(\pi)=\int_{0}^{t} \pi_{s} d S_{s}$ de gain process.

(iii) We say that $\mathbb{E}$-portfolio $\pi$ is admissible if it is self-financing and $\mathbf{E}\left[U^{-}\left(V_{T}(x, \pi)\right)+(-f)^{-}\left(g_{T}(\pi)\right)\right]<$ $\infty$, where $U$ is an utility function, $f$ a penalty function, and $U^{-}(x)=\max \{0,-U(x)\}$. The set of admissible portfolios will be denoted by $\mathcal{A}_{\mathbb{E}}(x, T)$.

In order to simplify we will make the following change of variable $\eta_{t}=\pi_{t} \frac{S_{t}}{V_{t}}$ and we denote the resulting wealth process by $V_{t}(x, \eta)$. Then

$$
d V_{t}(x, \eta)=\eta_{t} V_{t}(x, \eta) \frac{d S_{t}}{S_{t}}
$$

By equation (1) and Itô's formula, we have:

$$
V_{T}(x, \eta)=x e^{\int_{0}^{T} \eta_{t} d \widetilde{M}_{t}+\int_{0}^{T} \eta_{t}\left(\beta_{t}^{G}+\alpha_{t}\right) d\langle M\rangle_{t}-\frac{1}{2} \int_{0}^{T} \eta_{t}^{2} d\langle M\rangle_{t}} .
$$

For abuse of notation we will denote the respective set of admissible process by $\mathcal{A}_{\mathbb{E}}(x, T)$. Now the ordinary or honest trader has to solve the following problem

$$
\max _{\eta \in \mathcal{A}_{F}(x, T)} \mathbf{E}\left[U\left(V_{T}(x, \eta)\right)\right]
$$

and the insider has to solve

$$
\max _{\eta \in \mathcal{A}_{\mathbb{G}}(x, T)} \mathbf{E}\left[U\left(V_{T}(x, \eta)\right)-f\left(g_{T}(\eta)\right)\right]
$$

Now we consider the following case: $U(x)=\log (x)$ and $f(x)=\lambda_{2} x$, where $\lambda_{2}>0$ is interpreted as an exogenous proportional constant that represents the severity of the civil or criminal penalty due to the illegal trading. Furthermore, we assume that there is a probability $\lambda_{1}$ to be discovered by regulators and 
incur in penalties. Moreover, we assume that this probability is independent of the trading volume. ${ }^{7}$ Then, the insider problem turns into

$$
\max _{\eta \in \mathcal{H}_{\mathbb{G}}(x, T)} \mathrm{E}\left[\log \left(V_{T}(x, \eta)\right)-\lambda_{1} \lambda_{2}\left(g_{T}(\eta)\right)\right]
$$

where we define $g_{T}(\eta):=g_{T}\left(\frac{\pi}{V}\right)$.

Our main result is stated as follows: ${ }^{8}$

Theorem 1. If for all $l \in \mathcal{U}$ the process $\beta^{l} \in L_{\text {loc }}^{1}(M, \mathbf{P}, \mathbb{F})$, then an optimal strategy for the ordinary trader is given by $\eta^{\text {ord }}(t)=\alpha_{t}, t \in[0, T]$ and the corresponding maximal expected utility is given by

$$
\mathrm{E}\left[\log \left(V_{T}\left(x, \eta^{\text {ord }}\right)\right)\right]=\log x+\frac{1}{2} \mathbf{E}\left[\int_{0}^{T} \alpha_{t}^{2} d\langle M\rangle_{t}\right] .
$$

With the optimal strategy for the insider is given by

$$
\eta^{\text {ins }}=\left(1-\lambda_{1} \lambda_{2}\right)\left(\alpha_{t}+\beta_{t}^{G}\right), \quad t \in[0, T]
$$

the respective maximal expected utility is

$$
\mathbf{E}\left[\log \left(V_{T}\left(x, \eta^{\text {ins }}\right)\right)-\lambda_{1} \lambda_{2} g_{T}\left(\eta^{\text {ins }}\right)\right]=\log x+\frac{\left(1-\lambda_{1} \lambda_{2}\right)^{2}}{2} \mathbf{E}\left[\int_{0}^{T}\left(\left(\beta_{t}^{G}\right)^{2}+\alpha_{t}^{2}\right) d\langle M\rangle_{t}\right] .
$$

Observe that the above result holds also for $\lambda_{1}$ and $\lambda_{2}$ changing deterministically in time, i.e., we can consider $\lambda_{1}(t)$ and $\lambda_{2}(t)$.

Remark 1. It is interesting to see the following cases:

- If the probability to be captured is zero $\left(\lambda_{1}=0\right)$, then we have a full insider trading $\eta_{t}^{\text {ins }}=\beta_{t}^{G}+\alpha_{t}$, $\forall t \in[0, T]$.

- If the probability to be capture is one $\left(\lambda_{1}=1\right)$, then if we allow the penalty to change in time (more exactly $\lambda_{2}=\frac{\beta_{t}^{G}}{\alpha_{t}+\beta_{t}^{G}}$ ), we obtain $\eta^{\text {ins }}=\eta^{\text {ord }}$.

- If $0<\lambda_{1}<1$, and $0<\lambda_{2}<\infty,{ }^{9}$ such that $\lambda_{1} \lambda_{2} \gtrless 1$, Then, $\eta_{t}^{\text {ord }} \gtrless \eta_{t}^{\text {ins }}, \forall t \in[0, T]$.

- The additional utility of the insider is given by

$$
\frac{\left(1-\lambda_{1}(t) \lambda_{2}\right)^{2}}{2} \mathrm{E}\left[\int_{0}^{T}\left(\left(\beta_{t}^{G}\right)^{2}+\alpha_{t}^{2}\right) d\langle M\rangle_{t}\right]-\frac{1}{2} \mathrm{E}\left[\int_{0}^{T} \alpha_{t}^{2} d\langle M\rangle_{t}\right] .
$$

If $\lambda_{1} \lambda_{2}>2$, then this additional utility is positive. It give us an explanation of why there exist insider trading even though we have strong penalties i.e. a higher $\lambda_{2}$, since in real markets $\lambda_{1}$ is too small, for example if $\lambda_{1}=0.05$, we need a penalty $\lambda_{2}>40$ in order to discourage insider trading.

\footnotetext{
${ }^{7}$ We can say that this assumption is quite unrealistic since a high individual trading volume can become suspicious. On the other hand higher trading volumes do not necessarily result in higher gains.

${ }^{8}$ Its proof is presented in an Appendix at the end of this paper.

${ }^{9}$ Remember that by law the penalty is finite.
} 


\section{EXAMPLE}

Assume that our prices follow the Black and Scholes model, i.e., $M_{t}$ is given by $\sigma(t) B_{t}$ and $L=B\left(T_{0}\right)$, $T_{0} \geq T \geq t$, where $\left(\left\{B_{t}\right\}\right)_{\{t \geq 0\}}$ is a Brownian motion and the drift is denoted by $\mu(t)$. Then

$$
\pi^{\mathrm{ins}}(t)=\left(1-\lambda_{1} \lambda_{2}\right)\left[\frac{\mu(t)-r(t)}{\sigma^{2}(t)}+\frac{1}{\sigma(t)} \frac{B\left(T_{0}\right)-B(t)}{T_{0}-t}\right] .
$$

If we choose

$$
\lambda_{1}(t)=\frac{1-\left(T_{0}-t\right)^{\gamma}}{\lambda_{2}}, \quad \gamma>1 \quad \text { and } \quad \lambda_{2}>1-\left(T_{0}-t\right)^{\gamma}, \forall t,
$$

when $T_{0}=T<1$ we obtain a finite utility. This result avoids the unrealistic infinite utility found by Pikovsky \& Karatzas (1996).

\section{SIMULATIONS}

For our simulations we consider, as in the above example, the process $M_{t}=\sigma_{t} B_{t}$ for all $t \leq T$ and $T \leq T_{0} \leq 1$. We choose constant market coefficients $\mu(t)=0.00085$ and $\sigma(t)=0.035$ for all $t \leq T$, but the simulations could be easily extended to time-varying market coefficients. The annual interest rate is constant $r(t)=0.01$, for all $t \leq T$.

Now we consider a time-varying probability of being captured and punished $\lambda_{1}(t)=1-\left(T_{0}-t\right)^{\gamma}$, $\forall t \in[0, T]$ and $\gamma>1$, where we can understand $\gamma$ as the effectiveness of the regulator in detecting and punish the insider, a greater $\gamma$ means a more effective regulator. On the other hand, $\lambda_{2}$ represents the severity of the law penalty. In Figure 1, we show different portfolios for the ordinary and insider trader, when $\gamma=1.5$ and $\lambda_{2} \in\{1,2,3\}$.

Figure 1. Portfolios for different Penalty levels with $\gamma=1.5$. Parameters used in the simulations $\mu(t)=0.00085$, $\sigma(t)=0.035$ and $r(t)=0.01$ for all $t \leq T$.
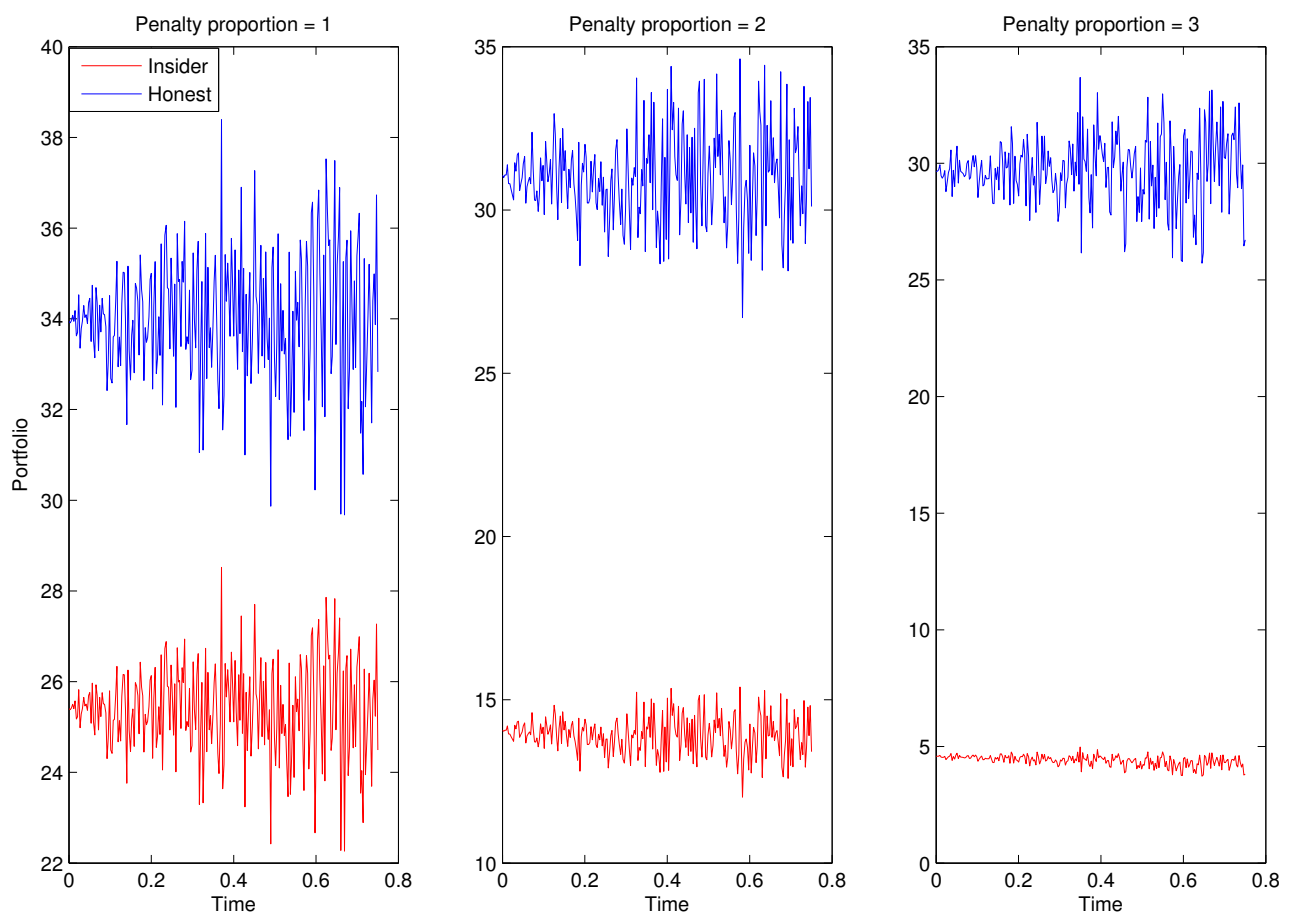
We can see that insider controls more her trading volume when penalty is higher, because the effectiveness of the regulator is quite considerable, with $\lambda_{1} \in[0.2845,0.2885]$. But if we consider a more effective regulator, namely $\gamma=3$, with $\lambda_{1} \in[0.4880,0.4932]$, even with less penalty the insider would need to control more her trade, as we can see in Figure 2.

Figure 2. Portfolios for different Penalty levels with $\gamma=3$. Parameters used in the simulations $\mu(t)=0.00085$ $\sigma(t)=0.035$ and $r(t)=0.01$ for all $t \leq T$.
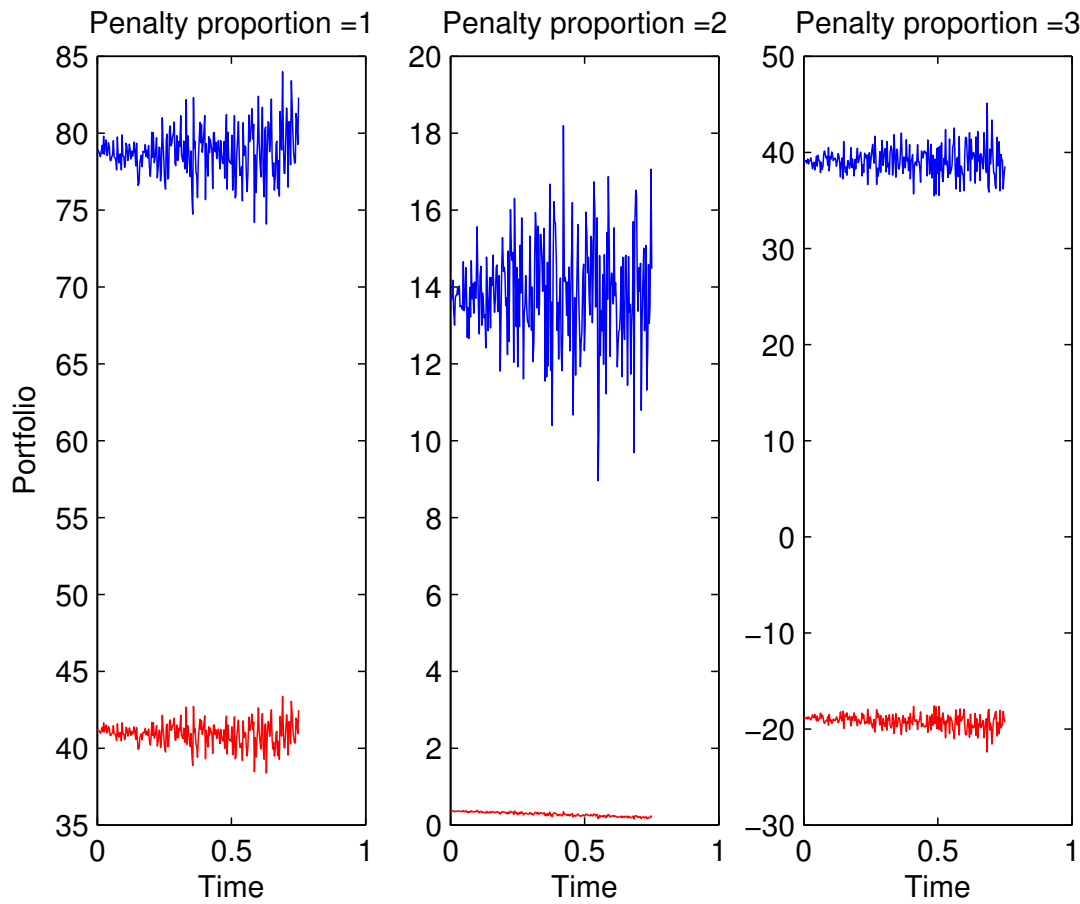

\section{OPTIMAL PENALTIES}

There is a debate in Law and Economics if we must penalize or not insider trading. This debate exists in both fields during a long time, and the main arguments pass through the main question: Is insider trading efficient in some sense or not? Even though we let insider trading to be a crime it could be the case that insider trading be Pareto improving, as proved by Zame (1993) in the case of default penalties.

Then, in our model we can ask: What is the penalty level that maximize the social welfare? That is, if we take both ordinary and insider traders and put together in a welfare function, it would be possible to find an optimal penalty level for insider trading, in the sense that penalty not to be too high, since then we can reduce drastically the volume, and not too low such that every body would desire to be an insider resulting in a no trade equilibria.

It is known that insider trading has some benefits since it contributes to more informative stock prices. ${ }^{10}$ On the other hand many critics of insider trading have argued that insider trading discourages investments due to information asymmetries, as was pointed out by Ausubel (1990). More recently, Acharya \& Johnson (2010) have shown that a greater number of insiders leads to more insider trading.

There are more empirical evidence that try to establish the impact of the enforcement of insider trading law in stock prices and liquidity, see Meulbroek (1992), Bhattacharya \& Daouk (2002), Ackerman,

\footnotetext{
${ }^{10}$ See Carlton \& Fischel (1983).
} 
Van Halteren, \& Maug (2008), Beny (2007), Fernandes \& Ferreira (2009).

In what follows we show a result consistent with the enforcement of insider trading law, that is we find that there is a penalty different from zero that maximize a social welfare function, in that sense we understand our penalty as an enforcement of the insider trading law. More exactly, we find that in our complete market case to forbid insider trading is the optimal enforcement rule.

Theorem 2. Assume that there are 2 traders: ordinary and insider. Then, given the optimal choices $\left(\eta^{h}\right)_{h \in\{\text { ord,ins }\}}$ and a probability $\lambda_{1}>0$, the optimal penalty for any $\gamma \in \mathbb{R}_{++}^{2}$,

$$
\lambda_{2}^{*} \in \underset{\lambda_{2}}{\arg \max } \sum_{h \in\{\text { ord,ins }\}} \gamma^{h}\left(\mathrm{E}\left[\log \left(V_{T}\left(x, \eta^{h}\right)\right)\right]\right)-\lambda_{1} \lambda_{2} \gamma^{\text {ins }}\left(\mathbf{E}\left[G_{T}\left(\eta^{\text {ins }}\right)\right]\right),
$$

is $\lambda_{2}^{*}=\infty$.

Proof. Follows directly from the specific solutions of the optimal strategies for the ordinary and insider traders.

It is important to notice that we are not assuming that this "welfare allocation" is an equilibrium allocation. To derive the correct equilibrium allocations we need the presence of a market maker.

\section{CONCLUSIONS}

In this paper we introduce law penalties to optimal insider trading models in a very simple way and show under mild conditions that there is a solution to the insider optimal strategy problem. Then, we analyze the penalty level that maximize a kind of social welfare function. We found that the full enforcement of insider trading law is optimal.

Our results indicates that legislators must try to increase the penalties to its possible maximum in order to discourage insider trading behavior. It is in line with the recommendation of Section 1079A(a)(1)(A) of the Dodd-Frank act that requires the U.S. Sentencing Commission to review its guidelines for security fraud offenses in order that penalties under these guidelines account appropriately for the potential and actual harm to the markets from such offenses.

Some important and interesting extensions to be done are the study of the equilibrium allocations and the analysis of the incomplete markets case.

\section{REFERENCES}

Acharya, V. V., \& Johnson, T. C. (2007). Insider trading in credit derivatives. Journal of Financial Economics, 84(1), 110-141. doi: 10.1016/j.jfineco.2006.05.003

Acharya, V. V., \& Johnson, T. C. (2010). More insiders, more insider trading: Evidence from private-equity buyouts. Journal of Financial Economics, 98(3), 500-523. doi: 10.1016/j.jfineco.2010.08.002

Ackerman, A., Van Halteren, J., \& Maug, E. (2008, February). Insider trading legislation and acquisition announcement: Do laws matter? In Efa 2006 zurich meetings. doi: 10.2139/ssrn.868708

Amendinger, J. (2000). Martingale representation theorems for initially enlarged filtrations. Stochastic Processes and their Applications, 89(1), 101-116. doi: 10.1016/S0304-4149(00)00015-6

Amendinger, J., Imkeller, P., \& Schweizer, M. (1998). Additional logarithmic utility of an insider. Stochastic Processes and their Applications, 75(2), 263-286. doi: 10.1016/S0304-4149(98)00014-3

Ausubel, L. M. (1990). Insider trading in a rational expectations economy. The American Economic Review, 80(5), 1022-1041. Retrieved from http://www.jstor.org/stable/2006759

Back, K. (1992). Insider trading in continuous time. Review of Financial Studies, 5(3), 387-409. doi: $10.1093 / \mathrm{rfs} / 5.3 .387$ 
Beny, L. (2007). Insider trading laws and stock markets around the world: An empirical contribution to the theoretical law and economics debate. Journal of Corporation Law, 32(2), 237-300.

Bhattacharya, U., \& Daouk, H. (2002). The world price of insider trading. The Journal of Finance, 57(1), 75-108. doi: $10.1111 / 1540-6261.00416$

Campi, L., \& Çetin, U. (2007). Insider trading in an equilibrium model with default: A passage from reduced-form to structural modelling. Finance and Stochastics, 11(4), 591-602. doi: 10.1007/s00780-007-0038-4

Carlton, D. W., \& Fischel, D. R. (1983). The regulation of insider trading. Standford Law Review, 35, 857-895.

Corcuera, J. M., Imkeller, P., Kohatsu-Higa, A., \& Nualart, D. (2004). Additional utility of insiders with imperfect dynamical information. Finance and Stochastics, 8(3), 437-450. doi: 10.1007/s00780-003-0119-y

DeMarzo, P., Fishman, M., \& Hagerty, K. (1998). The optimal enforcement of insider trading regulations. Journal of Political Economy, 106(3), 602-632. doi: 10.1086/250023

Di Nunno, G., Meyer-Brandis, T., Øksendal, B., \& Proske, F. (2006). Optimal portfolio for an insider in a market driven by Lévy processes. Quantitative Finance, 6(1), 83-94. doi: 10.1080/14697680500467905

Dubey, P., Geanakoplos, J., \& Shubik, M. (2005). Default and punishment in general equilibrium. Econometrica, 73(1), 1-37. doi: 10.1111/j.1468-0262.2005.00563.x

Elliott, R. J., \& Jeanblanc, M. (1999). Incomplete markets with jumps and informed agents. Mathematical Methods of Operations Research, 50(3), 475-492. doi: 10.1007/s001860050082

Fajardo, J. (2009). Pricing and optimality with default spreads. The Quarterly Review of Economics and Finance, 49(49), 686-692. doi: 10.1016/j.qref.2007.12.002

Fernandes, N., \& Ferreira, M. A. (2009). Insider trading laws and stock price informativeness. Review of Financial Studies, 22(5), 1845-1887. doi: 10.1093/rfs/hhn066

Grorud, A., \& Pontier, M. (1998). Insider trading in a continuous time market model. International Journal of Theoretical and Applied Finance, 1(3), 331-347. doi: 10.1142/S0219024998000199

Hsu, C.-H., \& Lee, H.-C. (2014). Insider trading and information revelation with the introduction of futures markets. Economic Modelling, 43, 173-182. doi: 10.1016/j.econmod.2014.07.037

Jacod, J. (1985). Grossissement initial, hypothèse $\left(H^{\prime}\right)$, et Théorème de Girsanov. In T. Jeulin \& M. Yor (Eds.), Grossissements de filtrations: Exemples et applications - Lecture Notes in Mathematics (Vol. 1118, pp. 15-35). Berlin: Springer-Verlag.

Jeanblanc, M., Yor, M., \& Chesney, M. (2009). Mathematical methods for financial markets. Springer-Verlag London. doi: 10.1007/978-1-84628-737-4

Kohatsu-Higa, A., \& Sulem, A. (2006). Utility maximization in an insider influenced market. Mathematical Finance, 16(1), 153-179. doi: 10.1111/j.1467-9965.2006.00266.x

Kyle, A. S. (1985). Continuous auctions and insider trading. Econometrica, 53(6), 1315-1335. doi: 10.2307/1913210

Liu, H., \& Zhang, Z. (2011). Insider trading with public and shared information. Economic Modelling, 28(4), 1756-1762. doi: 10.1016/j.econmod.2011.03.009

Ly Vath, V. (2007). Competitive market equilibrium under asymmetric information. Decisions in Economics and Finance, 30(2), 79-94. doi: 10.1007/s10203-007-0073-9

Meulbroek, L. K. (1992). An empirical analysis of illegal insider trading. The Journal of Finance, 47(5), 1661-1699. doi: $10.1111 / j .1540-6261.1992 . t b 04679 . x$

Pikovsky, I., \& Karatzas, I. (1996). Anticipative portfolio optimization. Advances in Applied Probability, 28(4), 1095-1122. doi: $10.2307 / 1428166$

Zame, W. R. (1993). Efficiency and the role of default when security markets are incomplete. The American Economic Review, 83(5), 1142-1164. Retrieved from http://www.jstor.org/stable/2117553

\section{APPENDIX. PROOF OF THE MAIN THEOREM}

Proof. From equation (4),

$$
\log \left(V_{T}(x, \eta)\right)=\log x+\int_{0}^{T} \eta_{t} d \widetilde{M}_{t}+\int_{0}^{T} \eta_{t}\left(\beta_{t}^{G}+\alpha_{t}\right) d\langle M\rangle_{t}-\frac{1}{2} \int_{0}^{T} \eta_{t}^{2} d\langle M\rangle_{t},
$$


and as $g_{T}(\eta)=\int_{0}^{T} \eta_{t} \frac{d S_{t}}{S_{t}}$ with equation (1), we have

$$
g_{T}(\eta)=\int_{0}^{T} \eta_{t} d \widetilde{M}_{t}+\int_{0}^{T} \eta_{t}\left(\beta_{t}^{G}+\alpha_{t}\right) d\langle M\rangle_{t} .
$$

Then

$$
\begin{array}{r}
\log \left(V_{T}(x, \eta)\right)-\lambda_{1} \lambda_{2} g_{T}(\eta)=\log x+\left(1-\lambda_{1} \lambda_{2}\right) \int_{0}^{T} \eta_{t} d \widetilde{M}_{t}+\left(1-\lambda_{1} \lambda_{2}\right) \int_{0}^{T} \eta_{t}\left(\beta_{t}^{G}+\alpha_{t}\right) d\langle M\rangle_{t} \\
-\frac{1}{2} \int_{0}^{T} \eta_{t}^{2} d\langle M\rangle_{t}
\end{array}
$$

and

$$
\begin{aligned}
& \log \left(V_{T}(x, \eta)\right)-\lambda_{1} \lambda_{2} g_{T}(\eta)=\log x+\left(1-\lambda_{1} \lambda_{2}\right) \int_{0}^{T} \eta_{t} d \widetilde{M}_{t} \\
&+\frac{1}{2} \int_{0}^{T}\left[\left(1-\lambda_{1} \lambda_{2}\right)\left(\beta_{t}^{G}+\alpha_{t}\right)\right]^{2} d\langle M\rangle_{t} \\
& \quad-\frac{1}{2} \int_{0}^{T}\left[\left(1-\lambda_{1} \lambda_{2}\right)\left(\beta_{t}^{G}+\alpha_{t}\right)-\eta_{t}\right]^{2} d\langle M\rangle_{t} .
\end{aligned}
$$

If $\mathrm{E}\left[\int_{0}^{T} \eta_{t}^{2} d\langle M\rangle_{t}\right]<\infty$, the local $\mathbb{G}$-martingale $\int_{0}^{T} \eta_{t} d \widetilde{M}_{t}$ would be a martingale, then would have expectation zero,

$$
\begin{aligned}
\mathbf{E}\left[\log \left(V_{T}(x, \eta)\right)-\lambda_{1} \lambda_{2} g_{T}(\eta)\right]=\log x & +\frac{1}{2} \mathbf{E}\left[\int_{0}^{T}\left[\left(1-\lambda_{1} \lambda_{2}\right)\left(\beta_{t}^{G}+\alpha_{t}\right)\right]^{2} d\langle M\rangle_{t}\right] \\
& -\frac{1}{2} \mathbf{E}\left[\int_{0}^{T}\left[\left(1-\lambda_{1} \lambda_{2}\right)\left(\beta_{t}^{G}+\alpha_{t}\right)-\eta_{t}\right]^{2} d\langle M\rangle_{t}\right],
\end{aligned}
$$

from here the maximal expected utility for the insider is attained at

$$
\eta^{\text {ins }}=\left(1-\lambda_{1} \lambda_{2}\right)\left(\beta_{t}^{G}+\alpha_{t}\right), \quad \forall t \in[0, T]
$$

Finally, it is easy to prove that $\psi^{\text {ins }} \in \mathcal{A}_{\mathbb{G}}$. The case of the ordinary trader is similar, it is enough to set $\lambda_{2}=0$ and $\beta^{G} \equiv 0$. 